\title{
Strategies of Constructing Shapes in Cabri
}

\author{
İbrahim Kepceoğlu ${ }^{1}$ \\ ${ }^{1}$ Department of Science and Mathematics Education, Faculty of Education, Kastamonu University, Kastamonu, \\ Turkey \\ Correspondence: İbrahim Kepceoglu, Department of Science and Mathematics Education, Faculty of Education, \\ Kastamonu University, Kastamonu, Turkey. Tel: 90-366-280-3414. E-mail: ikepceoglu@kastamonu.edu.tr
}

Received: August 8, 2018

Accepted: August 23, $2018 \quad$ Online Published: August 24, 2018

doi:10.5539/hes.v8n4p1

URL: https://doi.org/10.5539/hes.v8n4p1

\begin{abstract}
According to the constructivist approach in mathematics education, knowledge is actively created or invented by the students, not passively received from the teacher or the environment. In this regard, learning environments should be designed so that students have to use effectively their "own" knowledge and thus students achieve desired information. Through the micro-worlds, the experimental environments where students make observations, researches and predictions shall be created. In the micro-worlds formed by means of Cabri Geometry, a dynamic geometry sketchbook, users can draw and explore many geometric shapes. Besides, the manipulation and displacement of objects can be easily done via this software. In this study, we emphasize on that property of Cabri Geometry. Four pre-service elementary mathematics teachers among thirty ones which have taken a course on the mathematics teaching in the dynamic mathematics software environment have voluntarily participated to the study. The participants have randomly divided into two groups. Each group has worked on computer together and is asked to draw two dimensions shapes like triangles, parallelogram, rectangle etc. without using related "tool of Cabri". The collection of the data of this study involves interviews during their work, screen record of the computer and tape record of conversation among pair of participants. The results of study reveal that more professionally the participants use the Cabri Geometry more different strategies they use to construct asked shapes and participants have always questioned themselves about their pre-knowledge of the dynamically constructed shape.
\end{abstract}

Keywords: Cabri geometry, geometry instruction, dynamic shape

\section{Introduction}

Being one of the important branches of mathematics, geometry plays a crucial role in mathematics teaching for all educational levels. In many countries' mathematics curricula, there exist some educational attainments about geometry almost for every grade. In Turkey, the mathematics curricula have been changed in 2005 and students' active participation in learning mathematics and its principals has been chosen as the main aim of the new curricula. The program highlights the importance of a learning environment where the students may research, discover, solve problems, and where they can share and debate their solutions and approaches (MNE, 2015).

Furthermore, according to new curricula, teachers and students are encouraged to use any types of technology and Internet to teach and learn mathematics more concretely and meaningfully. Especially in geometry topics, dynamic geometric software with drag-mode capability such as Cabri has made possible the continuous variation of geometric configurations and allows students to quickly and easily investigate the truth of particular conjectures (de Villiers, 1998). This is related to distinction between drawing and figure. According to Laborde (1992), drawing is the trace of an object on paper while figure is the presented theoretical object. The importance of this distinction is heavily emphasized in dynamic geometric environments like Cabri environment. This program like other dynamic geometric software provide a model of Euclidean geometry which offers feedback through "dragging" as to whether constructions or theorems are "correct" (Hoyles \& Jones, 1998). But in contrast, in a "traditional" mathematics teaching environment, we usually draw an image of a 2-D geometric object on board without considerably thinking on its properties. Meanwhile to construct a geometrical object in a dynamic geometry software environment without using the exact tools requires a high level of geometric thinking.

Previous researches with dynamic geometry environments, especially with Cabri, whose focus on students' 
geometric-proof schemes reveal the fact that students develop and improve considerably their skills of reasoning in dynamic geometry environments. For example, in his paper, Nomura and Nohda discusses the change of reasoning that occurs using Cabri for the learning of geometry. The participant students were observed over a three year and students used Cabri in the classroom 10 hours per year. As a result of the study students explored the basic construction using their own knowledge, but in different ways than those in the text books. (Nomura \& Nohda, 1999).

In a similar study, Jones (2001) reported the data from a longitudinal study of students' interpretations of geometrical objects and relationships when using dynamic geometry software. The results of this study show that as the students worked through the teaching units, there was a shift in their thinking from imprecise, "everyday" expressions, through reasoning mediated by the software environment to mathematical explanations of the geometric situation.

In other study about proof in dynamic geometry environments, Leung (2009) discussed a 10th grade student's solution to a Sketchpad construction problem. This study shows that dynamic geometry environments (DGE) may serve as a reasonable justification to the original problems and that DGE proofs may re-shape "traditional" Euclidean proofs.

In this study, among the attainments of mathematics curricula, we focus on the ones that are related to the two dimensional basic shapes. The following question is chosen as the basic research question: "How do students construct the basic 2-D shapes such as square, quadrilaterals using the dynamic geometry software Cabri-Geometry?" The importance of our study relies on the current situation of geometry instruction in Turkey. Despite of the reforms in mathematics education and the encouragement of the use of the technology as stated before, the methods to teach geometry has been weakly changed. By this study, we aim to show how geometric thinking of students changes in dynamic geometry environment and how this change affects their knowledge about basic geometric shapes.

\section{Methodology}

In this study, the general methodology used for gathering and analysing information is the multiple case study procedure defined by Yin (2009). This procedure uses multiple case studies as replications, not as sampling procedure (Yin, 2009). "Multiple cases resemble multiple experiments" (Yin, 2009). Four pre-service elementary mathematics teachers among thirty ones which have taken a course on the mathematics teaching in the dynamic mathematics software environment have voluntarily participated to the study. Therefore, these four participants have a basic knowledge about the software Cabri. The participants have randomly divided into two groups. Each group has worked on computer together.

Both of two groups are asked to draw the following two dimensions shapes without using related "tool of Cabri" if exists:

- Scalene Triangle

- Isosceles Triangle

- Equilateral Triangle

- Parallelogram

- Rectangle

- Square

- Rhombus

- Deltoid

- Hexagon

The collection of the data of this study involves interviews during their work, screen record of the computer and tape record of conversation among pair of participants. Simultaneously with their work on computer, participants are interviewed about their strategies to draw the asked shape. In addition, researchers ask questions to control their construction in order to emphasize the distinction between drawings and figures. Meanwhile, all work done on the computer, even a wrong attempt in construction process, has recorded by free screen record software. That software records not also the visual work on the computer but also the conversation between group members. A tape recorder is also used to avoid any loss of data. 


\section{Findings}

The strategies that two groups chose to construct the shapes in Cabri environment can be summarized as in the following table.

Table 1 . Strategies used by the participants

\begin{tabular}{|c|c|c|}
\hline \multirow{2}{*}{ SHAPE } & \multicolumn{2}{|l|}{ STRATEGIES } \\
\hline & GROUP 1 & GROUP 2 \\
\hline $\begin{array}{l}\text { Scalene } \\
\text { Triangle }\end{array}$ & $\begin{array}{l}\text { Three points at random and the segments connecting } \\
\text { the points. }\end{array}$ & Three points at random and the segments connecting the points. \\
\hline $\begin{array}{l}\text { Isosceles } \\
\text { Triangle }\end{array}$ & One time rotation of a segment by a specific angle & A segment and two circles centered at the corners of the segment \\
\hline $\begin{array}{l}\text { Equilateral } \\
\text { Triangle }\end{array}$ & Two times rotation of a segment by $60^{\circ}$ angle & $\begin{array}{l}\text { A segment and two circles of radius the length of the segment at } \\
\text { the corners of the segment }\end{array}$ \\
\hline Parallelogram & Parallel lines from the corners of a segment & Parallel lines from the corners of a segment \\
\hline Rectangle & $\begin{array}{l}\text { Parallel and perpendicular lines from the corners of a } \\
\text { segment }\end{array}$ & $\begin{array}{l}90^{\circ} \text { rotation of a segment, construct a longer segment than the } \\
\text { first one and then parallel lines }\end{array}$ \\
\hline Square & Two times rotation of a segment by $90^{\circ}$ angle & $\begin{array}{l}\text { A circle at the center of the midpoint of a segment, a } \\
\text { perpendicular line from the same midpoint and the intersection } \\
\text { points of the circle and the line }\end{array}$ \\
\hline Rhombus & $\begin{array}{l}\text { Two times rotation of a segment by a specific angle } \\
\text { and its supplementary angle }\end{array}$ & $\begin{array}{l}\text { A segment, a circle through its corners, a rayon of the circle, two } \\
\text { lines parallel to the two radii, the intersection points of the lines }\end{array}$ \\
\hline Deltoid & $\begin{array}{l}\text { One time rotation of a segment by a specific angle, a } \\
\text { line through the midpoint of the constructed } \\
\text { segments, a point on the line }\end{array}$ & $\begin{array}{l}\text { A segment, a circle through its corners, a rayon of the circle, the } \\
\text { midpoint of two radii, a line through the center of the circle and } \\
\text { the midpoint, a point on the line }\end{array}$ \\
\hline Hexagon & $\begin{array}{l}\text { A segment and a circle through its corners, } 5 \text { times } \\
\text { rotation of the point on the circle by } 60^{\circ} \text { angle }\end{array}$ & 5 times rotation of a segment by $120^{\circ}$ angle \\
\hline
\end{tabular}

Some findings that give relatively more important results are given in this section.

\section{Isosceles Triangle - Group 2}

The group 2 members (they will be named as $2 \mathrm{~A}$ and $2 \mathrm{~B}$ ) try to connect three random points by segments like the previous "scalene triangle construction" and they measure their lengths.
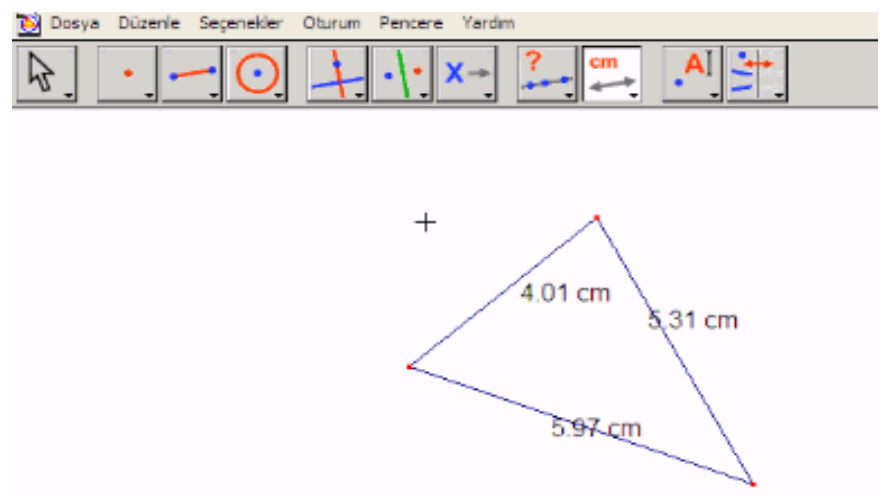

Figure 1

Then, the participants try to make their length equal by changing the places of the three points that they choose at first (See Figure 1). At this stage, they have the following conversation about the nature of the constructed triangle:

\section{A: This triangle cannot be always isosceles.}

2B: Yes. How do we it? 
2A: Two sides have to stay equal.

[Silence for a while and they move the points on the screen...]

2B: How can we do the segments with constant length?

2A: That is the problem. The length should be constant.

[A short silence]

2A: I guess we should try to use circles.

2B: Yes, circle but where?

[They try to construct some circles at different centers]

2B: Let's construct a circle with the endpoints of the first segment that we draw.

2A: Let's do it.(See Figure 2)

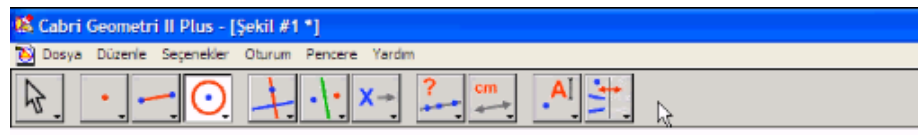

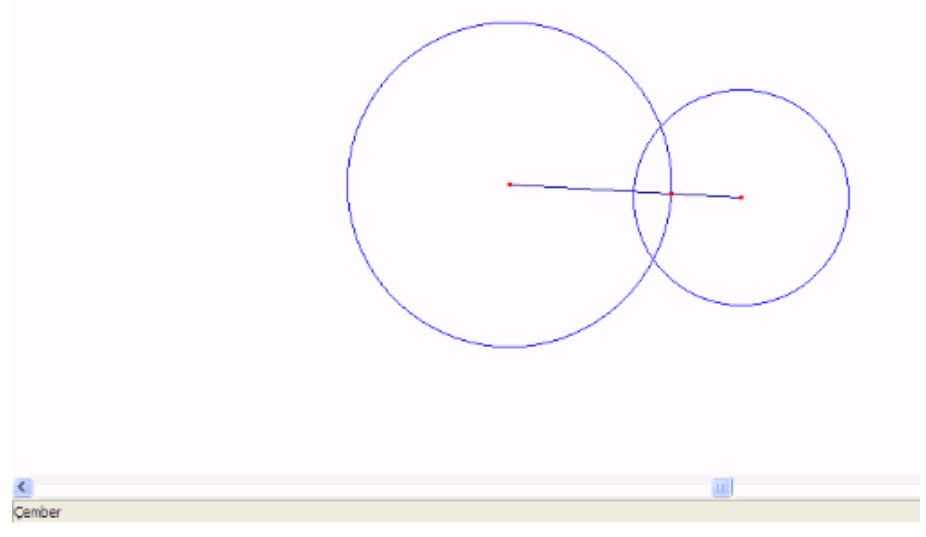

Figure 2.

2A: How will we change the lengths of the sides?

$2 B$ : What do you mean?

2A: That is supposed to be an isosceles triangle so do the equal sides have to be constant length? Can't it be changed?

$2 B$ : We can do it but I forgot how? Shall we ask to the teacher?

2A: Let's ask it.

At this moment, the researchers remind to the group members that with the aid of the tool "Compass", they can construct a circle from a center point with radius defined by a number or by a segment. Then, $2 \mathrm{~A}$ and $2 \mathrm{~B}$ determine a number with "Numerical Edit" tool and they choose that number as the radius of the circles. Afterwards, they obtain an isosceles triangle by connecting the endpoints of the segment with an intersection point of two circles. (See Figure 3) 


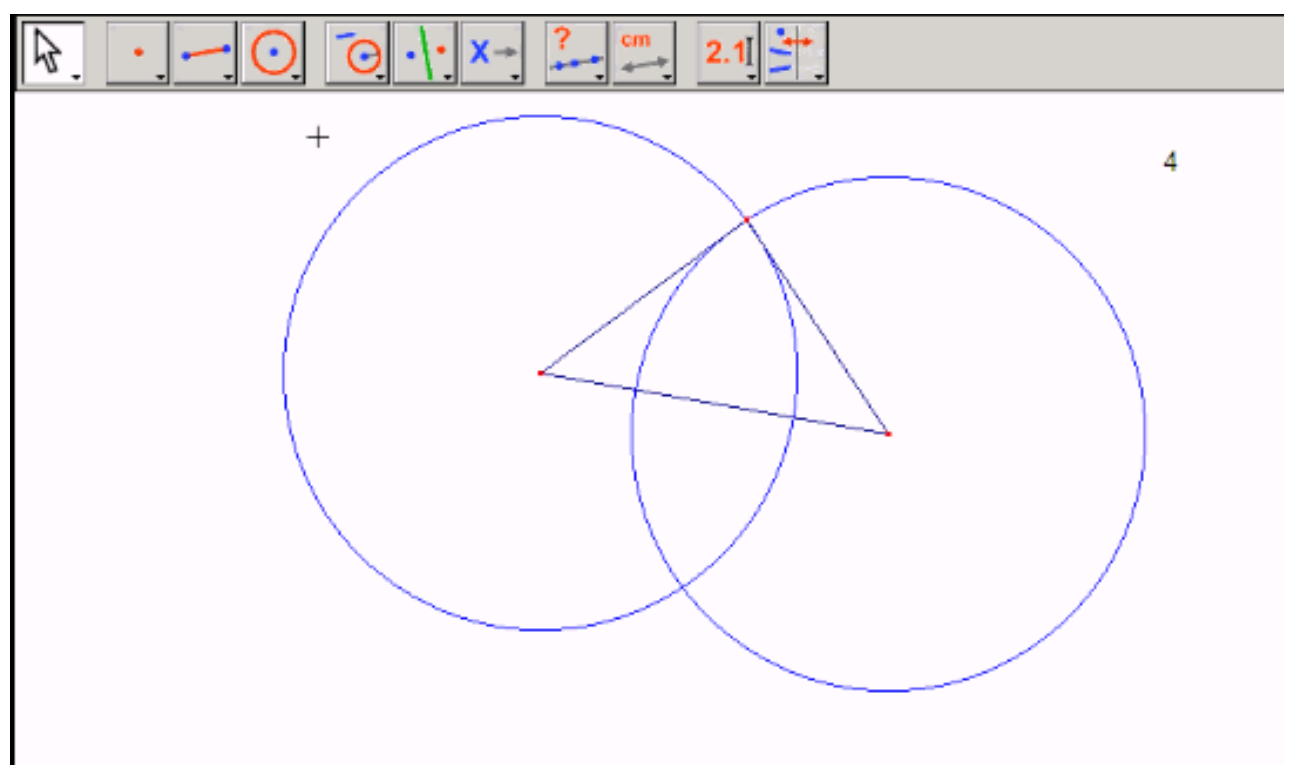

Figure 3.

Just after this construction, group members and researchers have a conversation about the nature of this shape. They try to decide whether it is a drawing or a dynamic figure:

Researcher: Does this shape stay always as an isosceles triangle?

2A: Yes, for example, let's change that number. [The number chosen for the radius of the circles on the screen is changed]

$2 B$ : Let's measure the side lengths.

Researcher: What if the base changes?

2B: Yes, circles are dependent on the endpoints of the base.

[Simultaneously, 2A makes a try and changes the base]

Researcher: Can you always have a triangle like this?

2A: Anytime if the triangle inequality holds. If not, we can increase the side lengths.

2B: Or decrease.

Researcher: Ok, that's nice!"

In this construction process, at the beginning, the group members have tried to construct an isosceles triangle in a non-dynamic manner. After their talk between them, they achieved to transform it to a dynamic figure. As they remember a property of Cabri Geometry, the "compass" tool, and the transformation from a drawing on the screen to a dynamic figure become more efficient.

\section{Deltoid - Group 1}

The group 1 members (they will be named as $1 \mathrm{~A}$ and $1 \mathrm{~B}$ ) firstly use the "rotation" tool which they use to construct previous shapes. They rotate a segment by a specific angular value defined by "numerical edit" tool. (See Figure 4) 


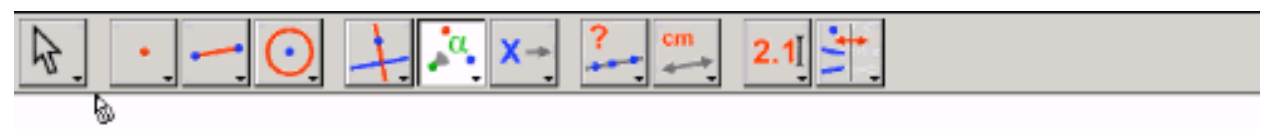

70

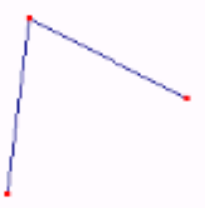

Figure 4.

Then, they construct a random line passing through the intersection corner point of two segments. After chose a point on that line, they think of completing the deltoid. (See Figure 5)

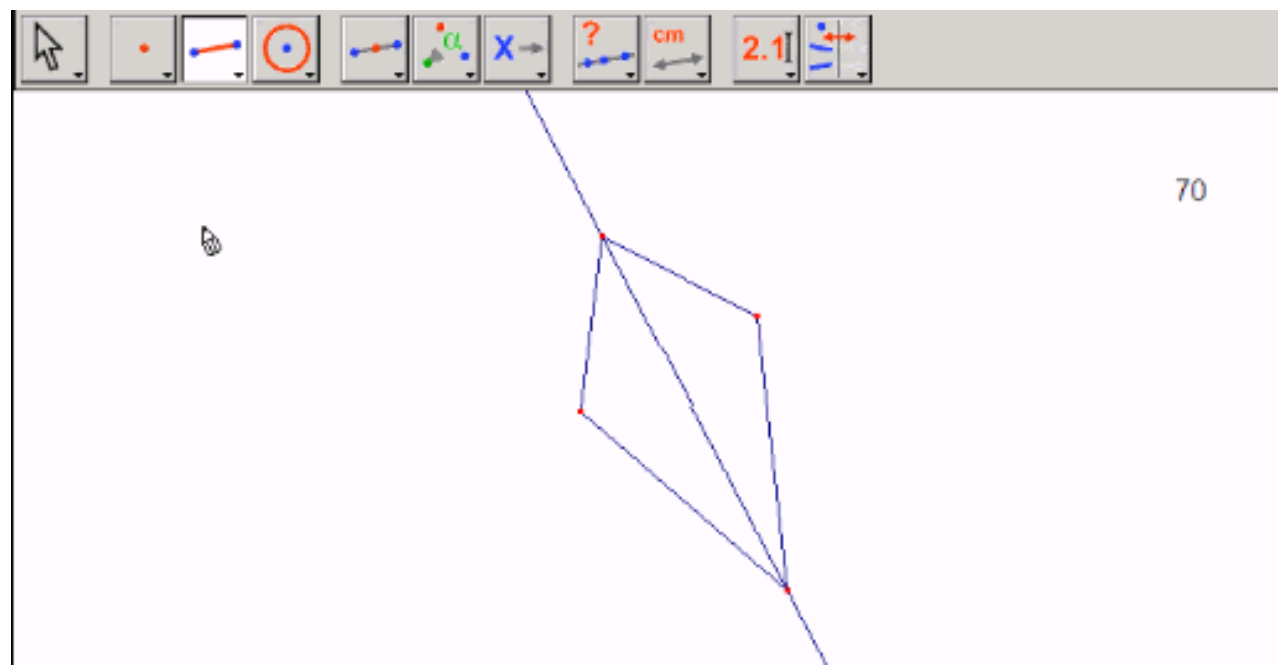

Figure 5 .

However, when they manipulate some free point on the figure, they realize that the image cannot be remain as a deltoid. Thereupon, they have the following conversation with the researchers:

Researcher $(R)$ : What did the shape change?

1A: It was look like a deltoid, but we move a point, it changed.

1B: So we didn't draw correctly.

1A: Yes, only its image was right.

1B: So, let's do not touch it, is it ok?

$R$ : Of course, not! What do you think why it is changing? Is this because of this angle?

1A: May be. After moving that point, let's change the angle, may be it will be a deltoid again.

[They manipulate a free point on the figure and they change the angle so that the image become again a deltoid]

1B: Now, it looks like again. 
1A: But we should not move the points.

1B: So, this is not true neither.

[They realize that the shape is changing. They try to decide what to do]

1A: We didn't draw the line correctly.

R: Yes, you should think of the properties of that line.

1B: That will be one of the diagonals

R: Right. What else?

1A: The diagonals are perpendicular to each other and they bisect each other.

IB: No, they do not bisect. How can they do? One of its sides is shorter.

1A: Yes, but these ones are isosceles triangles, aren't they?

1B: But from this perspective, the triangles aren't isosceles. So, the diagonals don't bisect. But as the upper and the lower triangles are isosceles, the horizontal diagonal has to be bisected.

1A: So, let's draw the horizontal diagonal. How can we find its midpoint?

1B: The midpoint...

1A: It must be somewhere here. I saw one time. Here I found.

[By using "midpoint" tool, they mark the midpoint of the diagonal.]

1B: Now, let's draw a line through the upper point and this point.

1A: I think it is ok.

$R$ : What if we move the free points?

1B: It won't change, look at it. (See Figure 6)

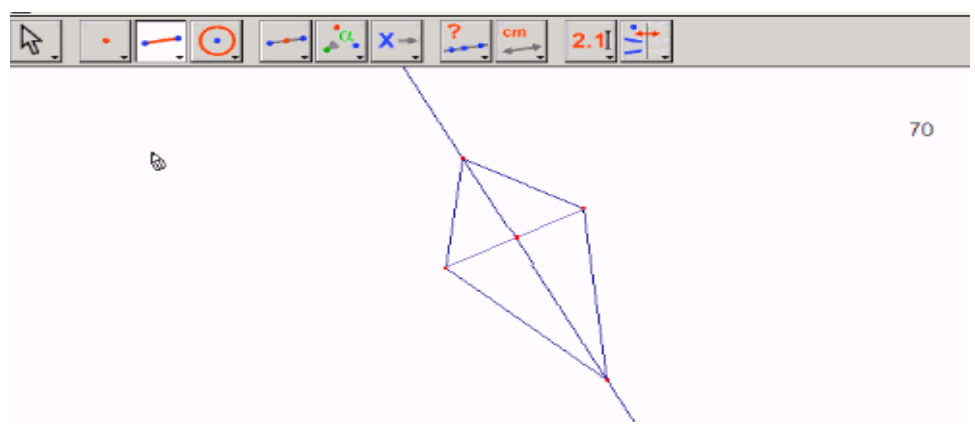

Figure 6.

In this construction process, the group members have difficulties related to the reason that they don't think on the basic properties of the constructed shape. After their first try, they don't construct a dynamic figure. Instead, they make a drawing. Due to the manipulation property of Cabri Geometry, they realize that the image obtained isn't dynamic as they want. Thereby, it can be inferred easily that Cabri environment provide opportunities to make numerous try in order to obtain the exact construction.

\section{Conclusions}

As a result of this study, it is revealed first of all that in order to construct asked shapes, participants have tried to use strategies which can be easily used in non-computer supported learning environments (blackboard, pencil, chalk). For instance, while construction an isosceles triangle, one group has tried to make two sides of a triangle equal in a random way. However, due to the Cabri Geometry's properties which are related to the displacement and the manipulation of objects, they have had opportunities to control what they have constructed. Such a control cannot be occurred when these shapes are drawn on a board.

Another important consequence of this study is that, in Cabri environment, participants have always questioned themselves about their pre-knowledge of the dynamically constructed shape. For example, in case of the construction of a rhombus or a deltoid, the perpendicular intersection of their diagonals is emphasized. Similarly, in case of a rectangle, they have mostly insisted on the property that the diagonals of a rectangle cannot be 
intersecting perpendicularly unless it is a square. From this result, it can be inferred that while making a dynamic construction in Cabri environment one has to use the basic properties of the shape. Otherwise, the shape on the screen will be only "a drawing". In other words, if a shape in a dynamic geometry environment is constructed without considerably thinking on its properties, that construction will be quiet similar to the drawings which are made during the "standard" courses with board and chalk. Thus, it can be deduced that a shape drawn on a board cannot reflect exactly all properties of the figures and that this drawing is just "an image" of the figure. Thereby the Cabri environment forces users to use a high level geometric thinking and improves as well the investigation skill of users.

Furthermore, other consequence of this study is that more professionally the participants use the Cabri Geometry more different strategies they use to construct asked shapes. This situation shows that, in Cabri environment, more than one way can be used for a construction and this is an important element in revealing and using different properties of the shapes. Thus, this property of dynamic geometry software has importance in transition of geometric thinking levels from the simple ones to more complexes.

\section{References}

De Villiers, M. (1998). An Alternative Approach to Proof in Dynamic Geometry. In R.Lehrer \& D.Chazan, (Eds.) Designing Learning Environments for Developing Understanding of Geometry and Space (369-395). Kentucky: Routledge.

Hoyles, C., \& Jones, K. (1998). Proof in Dynamic Geometry Contexts. In: C. Mammana \& V. Villani (Eds), Perspectives on the Teaching of Geometry for the 21st Century. Dordrecht: Kluwer.

Jones, K. (2001). Providing a foundation for deductive reasoning: students' interpretations when using dynamic geometry software and their evolving mathematical explanations. Educational Studies in Mathematics. Special issue on Proof in Dynamic Geometry Environments, 44(1-2), 55-85

Laborde, C. (1992). Enseigner la Géométrie: Permanences et Revolutions. In C. Gaulin, B. R. Hodgson, D. H. Wheeler \& J. C. Egsgard (Eds.) Proceedings of the $7^{\text {th }}$ International Congress on Mathematical Education. Canada: Quebec.

Leung, A. (2009). Written Proof in Dynamic Geometry Environment: Inspiration from a Student's Work. In F-L. Lin, F-J. Hsieh, G. Hanna \& M. de Villiers (Eds.) Proceedings of the ICMI Study 19 conference: Proof and Proving in Mathematics Education. Taiwan.

Ministry of National Education [MNE] (2015). İlköğretim Matematik Dersi (6-8 sınıflar) Öğretim Programı (Elementary School Mathematics Curriculum (grades 6-8)). Ankara, Turkey: MNE.

Nomura, T., \& Nohda, N. (1999). The Effects of Cabri-geometry for Exploring Geometry in the Classroom. Proceedings of the Fourth Asian Technology Conference on Mathematics. Guangzhou, China.

Yin, R. K. (2009). Case study research: Design and methods. Thousand Oaks, CA: SAGE Publications.

\section{Copyrights}

Copyright for this article is retained by the author(s), with first publication rights granted to the journal.

This is an open-access article distributed under the terms and conditions of the Creative Commons Attribution license (http://creativecommons.org/licenses/by/4.0/). 